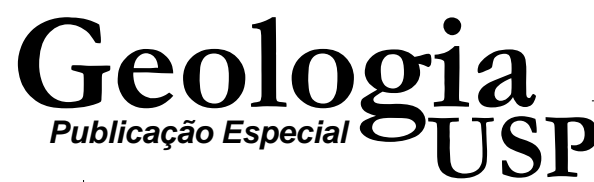

\section{Mineralogia: Disciplina Básica e Profissionalizante}

\author{
Fábio Ramos Dias de Andrade (dias@usp.br) e Eliane Aparecida Del Lama \\ Departamento de Mineralogia e Geotectônica - Instituto de Geociências - USP \\ R. do Lago 562, CEP 05508-080, São Paulo, SP, BRA
}

Recebido em 12 de dezembro de 2006; aceito em 29 de janeiro de 2007

Palavras-chave: mineralogia, currículo de Geologia, disciplina básica, disciplina profissionalizante.

\section{RESUMO}

O presente artigo discute a importância da Mineralogia no currículo de graduação (bacharelado) em Geologia, analisando em particular a situação no Instituto de Geociências da Universidade de São Paulo. Esta discussão foi desencadeada por possíveis mudanças que podem ocorrer nos campos tradicionais de atuação do geólogo, com base em nova resolução do Confea (Conselho Federal de Engenharia, Arquitetura e Agronomia) R1010. A Mineralogia é uma disciplina do segundo ano do curso de graduação em Geologia e é tradicionalmente considerada como uma disciplina básica. Entretanto, além de servir de base para Petrologia, Mapeamento Geológico, Geologia Econômica, entre outras disciplinas, a Mineralogia abre possibilidades concretas no campo profissional. Uma formação sólida em Mineralogia dá ao geólogo condições de aceitar desafios profissionais surpreendentes.

Keywords: mineralogy, curriculum of Geology, basic discipline, application discipline.

\begin{abstract}
This article discusses the importance of Mineralogy for the graduate Geology degree course at the University of São Paulo. The discussion started due to possible changes that may occur in the fields of occupation of geologists in the professional market, as new regulations have been proposed by the regulatory councils (Confea, Conselho Federal de Engenharia, Arquitetura e Agronomia, R1010). Mineralogy is a second-year course for undergraduate Geology students. Besides its' role as a basic course for Petrology, Geological Mapping, Economic Geology, among other courses, Mineralogy goes far beyond this, providing valuable professional skills. A solid formation in Mineralogy allows flexibility to the geologist to face the challenges in traditional and new fields.
\end{abstract}




\section{INTRODUÇÃO}

Este artigo faz parte da recente discussão sobre o currículo do curso de Geologia, desencadeada pela resolução R1010 do CONFEA (Conselho Federal de Engenharia, Arquitetura e Agronomia), que dispõe sobre a regulamentação da atribuição de títulos profissionais, atividades, competências e caracterização do âmbito de atuação dos profissionais inseridos no Sistema CONFEA/CREA, para efeito de fiscalização do exercício profissional.

A ampla gama de possibilidades de atuação do profissional de geologia tem provocado uma discussão sobre a importância de cada disciplina no currículo do Curso de Geologia, em termos de sua carga horária, conteúdo programático e encadeamento lógico seqüencial na grade curricular. A inserção de novas disciplinas na grade curricular, voltadas a campos científicos ou profissionais emergentes, requer uma contínua revisão do peso de cada disciplina no currículo atual.

Nos últimos anos, duas linhas de argumentação têm se contraposto: por um lado há os que defendem um currículo que enfatize uma sólida base científica e, por outro, os que preferem um currículo profissionalizante em essência, voltado às demandas do mercado de trabalho. Este confronto, entretanto, nem sempre é explícito e pode ocorrer de modo velado, no contexto da discussão sobre o espaço dado aos processos terrestres endógenos e exógenos no currículo de Geologia.

Apesar das controvérsias, é fato que a formação do geólogo é melhor hoje que aquela feita no passado, como foi apontado no II Encontro do Fórum Nacional de Cursos de Geologia (Carneiro e Assis, 2005).

Estudos sobre o ensino de Geociências indicam que a Mineralogia é tipicamente a primeira disciplina dos currículos de cursos de Geologia a tratar em profundidade temas relacionados às Ciências da Terra (Dutrow, 2004; Dyar, 2004). Isto se aplica ao curso de Geologia do Instituto de Geociências da Universidade de São Paulo (IGc-USP), pois a maioria das disciplinas do primeiro ano são básicas (Química, Física, Cálculo, Computação) ou introdutórias como Geologia Geral - Sistema Terra e Cristalografia - esta última, em particular, apesar de ser um pré-requisito natural e inquestionável para a disciplina de Mineralogia, não é uma disciplina de Ciências da Terra por natureza, pois se aplica à simetria do arranjo atômico na matéria cristalina de modo geral, sendo aplicada em Física, Geometria e Ciências dos Materiais, entre outros campos.

Este artigo apresenta a situação atual da disciplina de Mineralogia (GMG - 0220), em termos de sua estrutura didática e objetivos. Algumas questões aqui levantadas são consideradas relevantes: seria a Mineralogia uma disciplina básica? Seria a Mineralogia uma disciplina voltada aos fenômenos endógenos da Terra?
Questões decorrentes destas são discutidas, mas talvez a questão mais importante que tenhamos que ter em mente ao discutir a importância da Mineralogia no currículo de Geologia é se um currículo em Geociências pode ser explorado adequadamente sem o conhecimento básico sobre os minerais.

\section{ESTRUTURA DIDÁTICA}

A disciplina GMG-0220 Mineralogia é uma disciplina anual obrigatória do $2^{\circ}$ ano do curso de Geologia, ministrada em $2 \mathrm{~h}$ de aula teórica e $2 \mathrm{~h}$ de prática por semana, com um mínimo de 30 semanas letivas por ano, perfazendo 8 créditos. Nos demais cursos de Geologia pelo Brasil, esta disciplina apresenta de 4 a 18 créditos, indicando que a USP oferece a disciplina com número de créditos compatíveis com a média das outras universidades. A disciplina é ministrada por 3 docentes por semestre, acompanhados por monitores de graduação e pósgraduação, os quais participam das atividades práticas, em particular as de microscopia, onde os alunos demandam mais orientação individual. Considerando os quatro bimestres do ano letivo, o curso pode ser, grosso modo, dividido em um bimestre de mineralogia óptica, e três de mineralogia sistemática, sendo dois bimestres sobre silicatos e um sobre outras classes de minerais. Na mineralogia sistemática os minerais são abordados em termos de sua estrutura, composição, origem, métodos de identificação e princípios de classificação, com ênfase maior nos minerais formadores de rocha, em particular nos silicatos. A avaliação dos alunos é feita com base em quatro provas bimestrais teórico-práticas, além de trabalhos individuais e em equipe. Os trabalhos de pesquisa da literatura têm sido evitados, devido à prática cada vez mais disseminada de plágio integral de textos disponíveis na internet. A bibliografia recomendada para o acompanhamento do curso (Bloss, 1970; Tröger, 1979; Nesse, 1986; Deer et al., 1992; Klein e Hurlbut, 1993; Klein, 2002) cobre os aspectos teóricos e práticos necessários para o bom desempenho na disciplina, sendo de consulta obrigatória apesar de disponível apenas em língua estrangeira.

O conteúdo da disciplina de Mineralogia não se restringe às técnicas e procedimentos de laboratório, e abrange conceitos de Geologia, Física e Química. Não há uma seqüência ideal para a apresentação dos tópicos, uma seqüência intrínseca ao conteúdo do curso. A seqüência de tópicos adotada pelos professores é, portanto, dentre as muitas possíveis, aquela considerada mais conveniente para a apresentação completa da matéria.

No módulo inicial de óptica são abordados os fenômenos de interação da luz polarizada com a matéria cristalina translúcida, buscando fornecer aos alunos as informações necessárias para o entendimento dos princípios físicos que estão por trás do que se vê ao microscópio petrográfico. Este 
módulo habilita o aluno a usar todos os recursos disponíveis nos microscópios petrográficos convencionais, com aulas práticas e respectivo suporte teórico. As aulas práticas são cumulativas e incorporam conceitos de progressiva complexidade. Sem prescindir dos conceitos inicialmente vistos, os conceitos tornam-se mais complexos ao longo do curso. Apesar do caráter seqüencial desta abordagem do módulo de óptica, ao seu final o aluno pode perceber que os conceitos e procedimentos são decorrentes de um conjunto de fenômenos intrinsecamente relacionados em maior ou menor grau. Uma abordagem deste tipo é considerada por Dyar (2004) um aprendizado em espiral, onde cada novo conceito introduzido é repetido e reforçado na medida em que novos conceitos, mais avançados, são vistos. O aprendizado é um processo ativo onde o aluno constrói novos conceitos com base no seu conhecimento atual ou anterior, assimilando este novo conhecimento dentro de uma estrutura pré-existente. Este mecanismo de aprendizado se aproxima do construtivismo, processo pedagógico formalizado por Jean Piaget (1896 - 1980).

Com a prática em sala de aula, percebe-se a necessidade do tempo de amadurecimento e de familiarização com os minerais, com os conceitos, e com o microscópio petrográfico. A transposição para o mundo real observável das representações simplificadas, idealizadas em equações e modelos gráficos, exige contato continuado com os objetos de estudo, tendo em mente a relação entre teoria e prática. Os fenômenos da Física vistos em Mineralogia, apesar de relativamente simples, nem sempre encontram paralelo no mundo macroscópico à nossa volta, aquele que nos acostumamos a perceber na vida cotidiana. A prática em sala de aula demonstra que a maioria dos alunos apenas compreende a óptica cristalina como um conjunto integrado de conceitos alguns meses após o término do módulo introdutório de óptica, quando já pôde observar ao microscópio petrográfico diversas classes de minerais, que apresentam de modo mais ou menos pronunciado as propriedades ópticas conhecidas. Ao compreender os conceitos de mineralogia óptica como um conjunto consistente de modelos físicos e não como uma série de receitas a serem memorizadas e aplicadas em laboratório, o aluno pode lidar com as situações futuras, acadêmicas ou profissionais, que envolvam a análise e identificação de minerais e materiais cristalinos em geral.

Os três semestres seguintes enfocam a mineralogia sistemática, apresentando todos os minerais formadores de rochas e os principais acessórios. Uma ênfase maior é dada aos silicatos, por corresponderem a mais de $90 \%$ da crosta terrestre. A disciplina não pretende, por motivos óbvios, apresentar os mais de quatro mil minerais conhecidos, mas sim os minerais mais comuns e relevantes, que deverão ser reconhecidos por análise microscópica e, na medida do possível, também por análise macroscópica. Dentro de cada classe ou grupo de minerais se discute estrutura cristalina, simetria e composição química, correlacionando-as com propriedades macroscópicas, como cor, dureza e clivagem, entre outras. Sempre que disponíveis, os diagramas de fase são discutidos e interpretados, para se ter noção do campo de estabilidade dos minerais em termos de pressão, temperatura e composição.

Conceitos fundamentais da Mineralogia são apresentados ao longo do curso, aproveitando as particularidades das diversas classes e grupos de minerais. As soluções sólidas, por exemplo, são explicadas a partir dos feldspatos e rediscutidas nos casos subseqüentes, que incluem inossilicatos (piroxênios, anfibólios), olivinas e carbonatos, entre outros. A exsolução em função de queda da temperatura é melhor vista nos feldspatos alcalinos (pertitas, antipertitas), mas retomada sempre que perceptível em outros minerais, como nos orto- e clinopiroxênios. As transformações polimórficas são abordadas a partir das formas possíveis de $\mathrm{Al}_{2} \mathrm{SiO}_{5}$ (cianita, andalusita, sillimanita) e de $\mathrm{CaCO}_{3}$ (calcita, aragonita). O processo de metamictização é discutido em conjunto com os halos pleocróicos como, por exemplo, no contato entre minerais portadores de elementos radioativos (zircão, allanita) e biotita. Mesmo não sendo visível ao microscópio petrográfico, o politipismo é discutido em termos teóricos quando são abordados os argilominerais.

Os minerais opacos são vistos no bimestre final, de modo restrito às informações teóricas e análise macroscópica, pois não há tempo hábil para comportar um módulo de microscopia de luz refletida, que é apresentado em disciplina optativa.

A interpretação de diagramas de fase é vista ao longo dos três bimestres de mineralogia sistemática, de modo entrelaçado com os conceitos de polimorfismo, solução sólida, exsolução, reação em estado sólido, antecipando temas que serão vistos nas disciplinas subseqüentes de petrologia. $\mathrm{O}$ aluno recebe informação suficiente para, a partir de diagramas binários e ternários simples, identificar quais fases estão presentes, qual a composição química de cada fase e qual a proporção entre as fases em um dado ponto do diagrama.

As rochas não estão entre os objetivos da disciplina de Mineralogia, mas são usadas com freqüência para contextualizar as informações sobre os minerais. Durante as aulas práticas, procura-se apresentar as rochas (amostras didáticas) como sistemas químicos, o que restringe a identificação dos minerais a um número relativamente pequeno de possibilidades.

\section{DISCIPLINA BÁSICA E PROFISSIONALIZANTE}

A Mineralogia é uma disciplina básica para a maioria das disciplinas subseqüentes do currículo de Geologia, pois trata da caracterização das unidades fundamentais das rochas. Infelizmente, uma percepção presente nos meios acadêmicos é a de que a Mineralogia é uma disciplina básica no 
sentido restritivo do termo, i.e. se limita a uma preparação para as disciplinas de petrologia e demais disciplinas onde se faz necessária a identificação de minerais e rochas.

Se considerarmos as possibilidades profissionais do geólogo, vemos que a disciplina Mineralogia é também profissionalizante, com aplicações em pesquisa pura e aplicada, e junto à iniciativa privada. A existência de cursos de graduação em Mineralogia na Alemanha e em outros países é uma indicação de sua importância profissional. Os mineralogistas formados são requisitados em campos de trabalho em Geociências, Ciências dos Materiais e Física do Estado Sólido, e mesmo na indústria farmacêutica, onde a determinação dos parâmetros de estruturas cristalinas tem aplicação consolidada.

Mas não é apenas na tecnologia de ponta que se concentra o potencial de aplicação profissional dos mineralogistas e dos geólogos mineralogistas. A microscopia petrográfica é uma das mais antigas e importantes fontes de informação sobre os minerais, e seu custo é relativamente baixo em comparação com outras técnicas analíticas utilizadas em Geociências. A identificação e caracterização cuidadosa de minerais e compostos cristalinos sintéticos ao microscópio petrográfico é uma aplicação diária e corrente no setor mineral e da indústria de transformação no Brasil e no exterior.

O conhecimento prévio de aspectos estruturais e composicionais dos minerais e rochas, que pode ser obtido de modo rápido por microscopia óptica petrográfica, favorece grandemente o uso de métodos analíticos mais sofisticados, tais como difração de raios X, microscopia eletrônica de varredura e de transmissão, microssonda eletrônica, análises térmicas diferenciais e gravimétricas, inclusões fluidas, entre outras.

A Mineralogia está na base de uma série de aplicações tradicionais e inovadoras, dentre as quais enumeramos alguns exemplos:

1. petrografia em mapeamento geológico;

2. reconhecimento de minerais como indicadores em prospecção de jazidas;

3. caracterização e tratamento de minérios metálicos e não-metálicos, incluindo análises qualitativas e quantitativas de fases;

4. controle de processos industriais de transformação (e.g. cerâmica, cimento portland, vidro);

5. gemologia e síntese de materiais gemológicos;

6. mineralogia ambiental (minerais para controle de dispersão de poluentes; controle de patologias relacionadas ao contato com minerais, geologia médica);

7. preservação do patrimônio histórico (identificação de rochas, pigmentos, argamassas, azulejos antigos; determinação de proveniência e composição de objetos arqueológicos);

8. análises de novos materiais sintéticos (e.g. cerâmicas avançadas, fármacos).
Esta lista pode ser longamente estendida, considerando aplicações mineralógicas que vão da pedologia à análise de sólidos em suspensão na atmosfera, ou mesmo de materiais extraterrestre. Além disto, a estreita e crescente correlação entre a Mineralogia e a ciência dos materiais aponta para um grande potencial de aplicações em novos ramos das ciências puras e aplicadas.

\section{MINERALOGIA ENDÓGENA OU EXÓGENA?}

A divisão dos processos geológicos em endógenos e exógenos é um artefato arbitrário conveniente para a organização de diversas questões com as quais o geólogo se depara ao longo de sua formação e atividade profissional. Assim como a vasta maioria das classificações, esta também é falha se escrutinada em detalhe, pois tenta colocar limites em processos contínuos e graduais.

A tendência a se incluir a Mineralogia na "geologia endógena” não encontra respaldo na realidade. É fato que durante o aprendizado da identificação de minerais procuramos trabalhar com rochas com cristais bem formados e de bom tamanho, e com composição mineralógica suficientemente variada para permitir que o aluno veja as propriedades ópticas com mais facilidade. Dentre as rochas com estas características predominam as ígneas plutônicas e as metamórficas, que compõem a maior parte do acervo didático da disciplina.

Muitos dos minerais gerados por processos rasos ou superficiais na crosta terrestre são de difícil identificação por procedimentos rotineiros devido à sua granulometria fina, ou por sua complexidade estrutural e composicional, como no caso dos argilominerais interestratificados, cuja identificação requer não apenas um conjunto mais sofisticado de técnicas, como também uma experiência do usuário.

Entretanto, o curso de Mineralogia trata da matéria cristalina natural em suas propriedades intrínsecas estruturais e composicionais, não sendo conveniente subordiná-lo a uma eventual dicotomia “endógeno-exógeno”, cujos critérios são difusos e por vezes subjetivos.

\section{CONCLUSÃO}

O conteúdo da disciplina Mineralogia é extenso e introduz conceitos interdependentes e complexos, que exigem tempo de amadurecimento e estudo continuado. Uma formação completa e sólida em Mineralogia capacita o geólogo a enfrentar desafios profissionais nos campos tradicionais e novos do mercado de trabalho. Um currículo com forte base científica não exclui a profissionalização, ao contrário, forma profissionais com flexibilidade para atuar em diferentes áreas, estimula o espírito crítico e a criatividade.

Não se aprende Mineralogia com apostilas e cursos rápidos. 


\section{REFERÊNCIAS BIBLIOGRÁFICAS}

BLOSS, F. D. Introducción a los métodos de la cristalografia óptica. Madrid: Omega, 1970. 320 p.

CARNEIRO, C. D. R.; ASSIS, J. F. P. Relato final do II Encontro do Fórum Nacional de Cursos de Geologia. Belém, maio de 2003. Terrae Didática, Campinas, v. 1, n. 1, p. 74-83, 2005. Disponível em: <http://www.ige.unicamp.br/terraedidatica $>$. Acesso em: 21 nov. 2006.

DEER, W. A.; HOWIE, R. A.; ZUSSMANN, J. An introduction to the rock-forming minerals. Essex: Longman Scientific \& Technical: Wiley, 1992.691 p.

DUTROW, B. L. Teaching mineralogy from the core to the crust..Journal of Geoscience Education,Washington, v. 52, n. 1, p. 81-86, 2004.

DYAR, M. D. Integration of new methods in teaching mineralogy. Journal of Geoscience Education, Washington, v. 52, n. 1, p. 23-30, 2004.

KLEIN, C. Mineral sciences. New York: J. Wiley \& Sons, 2002.681 p.

KLEIN, C.; HURLBUT, C. S. Manual ofmineralogy. 21. ed. New York: J. Wiley \& Sons, 1993. 681 p.

NESSE, W. D. Introduction to optical mineralogy. New York: Oxford University Press, 1986. 325 p.

TRÖGER, W. E. Optical determination of rock-forming minerals. Part 1, determinative tables. Stuttgart: Schweizerbart, 1979. 188 p. 